\title{
Flora da Bahia: Violaceae e estudos taxonômicos no gênero Paypayrola Aubl.
}

\section{$\underline{\text { Filipe Gomes dos Anjos Oliveira }}^{\mathbf{1}}$, José Florencio Cerqueira Oliveira $^{2}$; Luciano Paganucci de Queiroz ${ }^{3}$}

1, 2. Bolsista PIBIC/CNPq, Graduando em Ciências Biológicas, Universidade Estadual de Feira de Santana, e-mail:

filipegomes335@gmail.com, jose.florencioco@gmail.com

3. Professor Dr. Do Departamento de Ciências Biológicas, Universidade Estadual de Feira de Santana, e-mail: luciano.paganucci@gmail.com

PALAVRAS-CHAVE: Taxonomia; Florística; Malpighiales.

\section{INTRODUÇÃO}

Violaceae possui distribuição cosmopolita e inclui 23 gêneros e cerca de 800 espécies. No Brasil ocorrem 14 gêneros e cerca de 80 espécies, a maioria em Pombalia Vand. e Rinorea Aubl. (Souza e Lorenzi 2012; Paula-Souza, 2009).

As Violaceae são ervas, árvores ou, menos frequentemente, lianas com folhas alternas espiraladas ou dísticas ou, menos frequentemente, opostas, simples, com estípulas conspícuas, persistentes ou caducas, raramente com pontuações translúcidas (Leonia Ruiz \& Pav.), inflorescência em pseudoracemo, racemo, cimeira simples ou composta, fascículo ou flores solitárias, flores geralmente bissexuadas, actinomorfas a fortemente zigomorfas, diclamídeas, cálice pentâmero, dialissépalo, persistente na frutificação, imbricado, labelo (pétala abaxial) giboso a longamente calcarado nas flores zigomorfas, estames (3-)5, filetes livres ou unidos entre si, anteras rimosas, geralmente com conectivo provido de um apêndice membranáceo e apical (em algumas espécies os dois estames anteriores, são provido de apêndices nectaríferos sobre os filetes), ovário súpero, (2-)3(-5)-carpelar, unilocular, placentação parietal, uni a pluriovulado, fruto cápsula, às vezes membranácea e inflada (Anchietea e Hybanthopsis), raramente baga (Gloeospermum Triana \& Planch. e Leonia) ou noz (Leonia) (Souza \& Lorenzi 2012).

A família tradicionalmente é dividida em três subfamílias (Hekking 1988): Leonioideae, com flores actinomorfas, prefloração irregularmente imbricada, representada apenas pelo gênero sul-americano Leonia; Violoideae, com flores actinomorfas ou zigomorfas, prefloração coclear distal ou quincuncial e Fusispermoideae, com flores actinomorfas, prefloração convoluta, representada pelo gênero Fusispermum Cuatrec. Paula-Souza (2009) realizou estudos filogenéticos na tribo Violeae e observou que Violoideae não é monofilética. Nesse mesmo trabalho também foi constatado o não monofiletismo de Hybanthus o que levou ao restabelecimento de Pombalia (Paula-Souza 2014), transferindo assim para este último gênero várias espécies listadas para a Bahia. No entanto, algumas espécies foram mantidas em Hybanthus mesmo apresentando características que sustentariam sua transferência para Pombalia. Essa mesma autora aponta a necessidade de uma melhor diferenciação entre Pombalia e Hybanthus (Paula-Souza 2009).

Apesar dos avanços no conhecimento da família, não existe um estudo taxonômico para o gênero Paypayrola, o que resulta em muitas confusões quanto a delimitação das espécies, sendo este o principal objetivo do presente trabalho. 


\section{MATERIAL E MÉTODOS}

Foram realizadas expedições para amostragem das espécies nativas da Bahia, especialmente os gêneros mal representados nos herbários. Foram priorizadas viagens para municípios onde havia informação de presença de espécies pouco coletadas, tendo sido selecionadas municípios da Chapada Diamantina (Abaíra, Catolés, Ituaçu e Tanhaçu).

Foram analisadas as coleções dos principais herbários da Bahia (ALCB, CEPEC, HUEFS). Tipos nomenclaturais de táxons da Bahia foram analisados através de imagens disponibilizadas na internet, especialmente no site do JStor Plant Science (http://plants.jstor.org), do Species Link (http://splink.cria.org.br/) e do Reflora (http://floradobrasil.jbrj.gov.br/).

As espécies foram identificadas através da análise das obras príncipes e comparação com imagens dos tipos nomenclaturais disponíveis. As descrições morfológicas foram feitas com base em espécimes coletados na Bahia. Eventualmente, espécimes coletados fora do estado poderão ser usados para complementar à descrição de partes ausentes.

\section{RESULTADOS E DISCUSSÃO}

$\mathrm{Na}$ Bahia foram catalogados nove gêneros e 25 espécies. O maior gênero é Pombalia, com doze espécies: P. arenaria (Ule) Paula-Souza, P. atropurpurea (A.St.Hil.) Paula-Souza, P. barbata Paula-Souza, P. brevicaulis (Mart.) Paula-Souza, P. calceolaria (L.) Paula-Souza, P. communis (A.St.-Hil.) Paula-Souza, P. glauca (Chodat) Paula-Souza, P. heterosepala (Eichler) Paula-Souza, P. lanata (A.St.-Hil.) Paula-Souza, P. oppositifolia (L.) Paula-Souza, P. setigera (A.St.-Hil.) Paula-Souza, $P$. verrucosa (Paula-Souza) Paula-Souza. Os demais gêneros encontrados na Bahia são: Amphirrhox Spreng. (1 espécie), Anchietea A.St.-Hil. (3), Hybanthopsis Paula-Souza (1), Hybanthus Jacq. (1), Noisettia Kunth (1), Paypayrola Aubl. (2), Rinorea Aubl. (3), Schweiggeria Spreng. (1). Anchietea ferrucciae Paula-Souza \& Zmarzty e Pombalia heterosepala são endêmicas da Bahia. Hybanthopsis bahiensis Paula-Souza, anteriormente considerada endêmica da Bahia, foi recentemente registrada para a Serra da Guia no estado de Sergipe.

Os estudos taxonômicos no gênero Paypayrola ainda se encontram em processo de conclusão. Porém, as análises realizadas neste período indicam que Paypayrola conta com oito espécies: Paypayrola arenacea Aymard \& G.A. Romero, Paypayrola blanchetiana Tul., Paypayrola confertiflora Tul., Paypayrola glazioviana Taub., Paypayrola grandiflora Tul., Paypayrola guianensis Aubl., Paypayrola hulkiana Pulle., Paypayrola longifolia Tul.

\section{Chave para os Gêneros de Violaceae da Bahia}

1. Habito não arbóreo; flores claramente zigomorfas

2. Arbusto escandente

3. Trepadeiras; folhas com base cordada; sementes pilosas com duas projeções na base Hybanthopsis

3. Lianas; folhas com base aguda a cuneada; sementes glabras sem projeções na base Anchietea

2'. Erva; arbusto ou subarbusto 
4. Três sépalas externas e duais internas; estigma trilobado (sendo um dos lobos pouco visível)

Schweiggeria

4'. Todas as sépalas externas; estigma simples

5. Inflorescência em fascículos axilares

Noisetia

5'. Inflorescência dispostas de outra forma

6. Papilas na face abaxial das folhas, gineceu e androceu ........ Hybanthus

6'. Papilas ausentes em toda a planta.

Pombalia

1'. Hábito arbóreo; flores actinomorfas ou levemente zigomorfas

7. Flores não tubulares; estames livres entre si, raramente fundidos na base ..... Rinorea

7 . Flores tubulares; estames fundidos na base

8. Inflorescência em dicásio; estilete maior que $5 \mathrm{~mm}$ compr.; apêndice do conectivo afilado no ápice da antera (cerca de $2 \mathrm{~mm}$ compr.).....Amphirrhox

8'. Inflorescência racemosa; estilete menor que $4 \mathrm{~mm}$ compr.; apêndice do conectivo retangular no ápice da antera (ca. $1 \mathrm{~mm}$ compr.)

Paypayrola
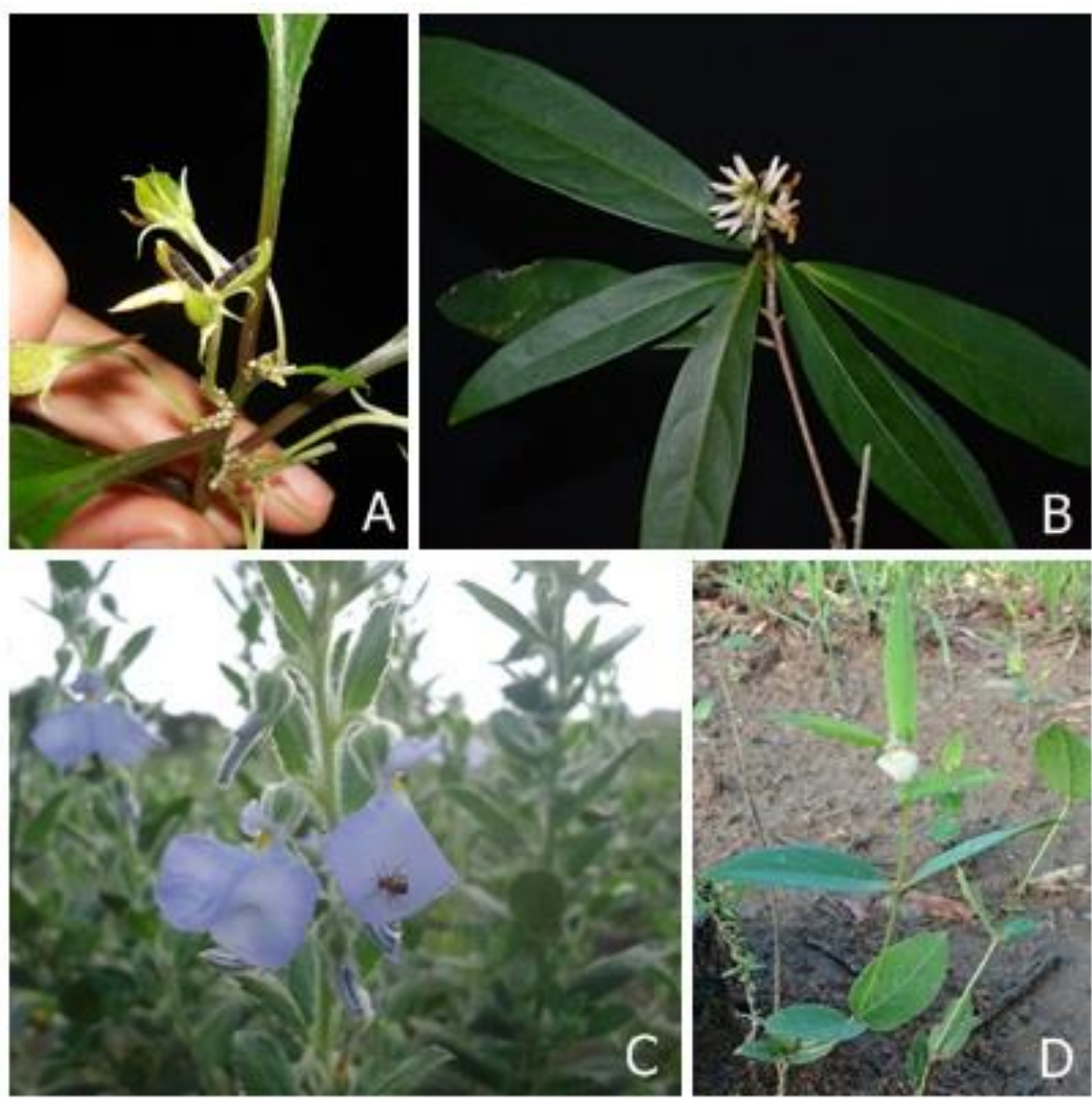

Figura 1: Espécies de Violaceae da Bahia. A - Noisettia orchidiflora; B - Paypayrola blanchetiana; C - Pombalia arenaria; D - Pombalia glauca. Foto A: Lucas Marinho; Foto B: Moabe Fernandes. 


\section{CONSIDERAÇÕES FINAIS}

A família Violaceae apresenta ampla distribuição no estado da Bahia, tendo o gênero Pombalia o maior número de representantes no estado. Ainda se fazem necessárias excursões botânicas para amostragem das espécies pouco representadas em herbários. Maiores estudos ainda devem ser realizados para a delimitação das espécies presentes no gênero Paypayrola.

\section{REFERÊNCIAS}

Aymard-C, G. et al. 2014. Paypayrola arenacea (Violaceae), a new species with an unusual life-form from a white sand savanna in the Amazon river basin of Venezuela. Harvard Papers in Botany. Vol. 19, No. 2, pp. 175-184.

Hekking, W. H. A. 1988. Monograph 46. Violaceae Part I - Rinorea and Rinoreocarpus. Flora Neotropica Monograph 26: 1-207.

Paula-Souza, J. 2003. Levantamento das espécies de Hybantus Jacq. (Violaceae) do Brasil. (Mestrado). Univ. São Paulo.

Paula-Souza, J. 2009. Estudos Filogenéticos em Violaceae com ênfase na Tribo Violeae e Revisão Taxonômica dos Gêneros Lianescentes de Violaceae na região Neotropical. (Doutorado). Univ. São Paulo. 259p.

Souza, V.C. \& Lorenzi, H. 2012. Botânica Sistemática: guia ilustrativo para identificação das famílias de fanerógamas nativas e exóticas no Brasil, baseado em APG II. $3^{\text {a }}$ ed. $768 \mathrm{p}$. 